\title{
Yeserías epigrafiadas del Castillo de Santa Catalina (Jaén)
}

\author{
Ma Antonia Martínez Núñez *
}

\begin{abstract}
RESUMEN
Este artículo se centra en el estudio de unas yeserías, de cronología almohade, que aparecieron en las excavaciones arqueológicas realizadas en el año 200 I en el castillo de Santa Catalina de Jaén. Se ofrece la lectura y la traducción de la inscripción, que discurre por un friso o banda epigráfica, y el análisis de sus rasgos gráficos, decorativos y textuales, así como de los restantes motivos ornamentales de las yeserías.
\end{abstract}

PALABRAS CLAVE: al-Andalus. Almohades. Epigrafía. Decoración arquitectónica.

En el curso de unas excavaciones arqueológicas de apoyo a la restauración ', realizadas en el año 200 I en el Castillo de Santa Catalina (Jaén), aparecieron, entre otros materiales, varios fragmentos de yeserías. Según los arqueólogos responsables de la intervención, formaban parte de dos paneles decorativos de una puerta de doble arcada, perteneciente posiblemente a una zona palatina del recinto.

Estos materiales incluyen restos de sendos paneles de aturique, con enmarques de lacería, fragmentos de las dovelas de dos arcos, alternando dovelas lisas con otras decoradas en ataurique, y restos de un friso o banda epigráfica.

\begin{abstract}
This article is centered in the study of some plasterworks, of almohad chronology, which appeard in the archaeological excavations carried out in the year 200 I in the Castle of Santa Catalina in Jaén. Here is offered the reading and the translation of the inscription, that reflects for a wainscot or epigraphic band, and the analysis of their graphic, ornamental and textual features, as well as of the remaining ornamental reasons of the plasterworks.
\end{abstract}

KEY WORDS: al-Andalus. Almohads. Epigraphy. Architectural decoration.

\section{LA INSCRIPCIÓN}

El material epigráfico conservado corresponde a dos fragmentos, que casan entre sí, de una misma banda epigráfica. Las numerosas roturas que se observan no afectan a la parte fundamental del cuerpo de los grafemas, por lo que su lectura no ofrece gran dificultad. Presenta una línea de escritura en caracteres cúficos, labrados en resalto, con elementos decorativos entre los trazos altos y como delimitación del campo epigráfico, sendos filetes también tallados en relieve. El primer fragmento (Lám. I) mide $40 \mathrm{~cm}$. de largo y el segundo (Lám. 2) $45 \mathrm{~cm}$. La altura máxima es de 1370 cm., con

\footnotetext{
* Departamento de Filología Griega, Estudios Árabes, Lingüística General y Documentación. Facultad de Filosofía y Letras. Universidad de Málaga.

I A cargo de los arqueólogos Juan Carlos Castillo Armenteros y Vl' del Carmen Pérez Martínez, quienes solicitaron mi colaboración para el estudio del material epigráfico.
} 
II cm. en el campo epigráfico y entre I'I0 y I'20 cm. en los filetes.

\section{LECTURA Y TRADUCCIÓN}

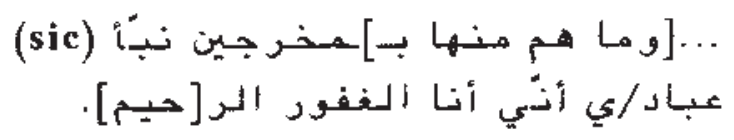

[...y de ellos no serán] expulsados (Q. XV, 48). Informa a Mis servidores de que Yo soy el Indulgente, el Misericordioso (Q. XV, 49).

El contenido coránico de la inscripción obliga a intentar determinar su posible cronología en función del análisis de los elementos disponibles: tipo y diseño de la grafía utilizada, motivos ornamentales que la acompañan y uso de los versículos coránicos reproducidos.

\section{ANÁLISIS DE LA GRAFÍA}

El epígrafe está realizado en un cúfico simple evolucionado, en el que destaca la gran prolongación en vertical de los trazos altos, o astas, que llegan hasta el borde mismo del filete superior. Las terminaciones a bisel de las astas son rectas y austeras, sin retrocesos en escuadra, al menos en los fragmentos conservados, ni remates foliados, lobulados o geométricos.

La horizontalidad de la línea de base de escritura está muy marcada y discurre en paralelo y a una distancia constante (I'I8 cm.) del filete inferior. En torno a la línea de base se articula toda la composición gráfica: en la parte superior, más amplia y de mayor relieve, se ubi- can las prolongadas astas, los ornatos para rellenar los huecos dejados entre ellas y los cuerpos del resto de los grafemas, algunos de los cuales, como los trazos 10 m ( $f a ̈$ en posición medial) y $16 f$ (wāw en posición final), presentan un pedúnculo o cuello que permite insertarlos en la línea de base. De dicha línea arrancan, en la parte inferior, los pronunciados nexos curvos y los apéndices finales de los grafemas, descansando ambos sobre el filete inferior.

Esa forma de estructurar los diferentes grafemas en torno a la línea de base es característica de la epigrafía del siglo XII en adelante, especialmente destacable en el cúfico de cronología almohade y tanto en las inscripciones monumentales de la dinastía mu'miní ${ }^{2}$ como en los epígrafes funerarios de ese periodo ${ }^{3}$.

La austeridad en las astas podría en principio remitir a una cronología algo anterior a la almohade. Sin embargo, esa misma austeridad se mantuvo en una de las variantes del cúfico almohade, representada en algunas leyendas eulógicas del minarete de la Kutubiyya (BASSET, TERRASSE, 200 I: pp. 122-123, fs. 40 a y 40 b) o en las bandas epigráfícas de las puertas monumentales de Marruecos (MARTíNEZ NUÑEZ, 1997a: pp. 429-432, Im. 3, fs. I y 2), mientras que en al-Andalus esa variante se encuentra en el fragmento de un gran epígrafe en piedra (PAVÓN, 1981: pp. 8-9, f 3, Ims. VI b y c), procedente, al parecer, de una-de las puertas de la muralla de Jerez de la Frontera ${ }^{4}$, y en inscripciones funerarias del Levante peninsular, como la mqābriyya de Játiva, ya citada (véase nota 3), la estela del 579/ | 18 | de la Almonia de Valencia (LABARTA, BARCELÓ, 1992: pp. 540-543) o una mqābriyya, también valenciana, de finales del siglo XII o principios del XIII (BARCELÓ, 1998: nº 44, Ims. XLV-XLVII),

\footnotetext{
2 Así se observa en las bandas en cúfico de las puertas monumentales de Rabat y Marrakech e incluso en los motivos-tipo (MARTíNEZ NUÑEZ, I997a: pp. 430-43I, Ims. 3 y 4).

3 Como en la mqábriyya de Játiva, en la malagueña de mármol de 1221 y en la de cerámica vidriada en verde, también procedente de Málaga (FERNÁNDEZ PUERTAS, 1978-79: pp. 226-228; BARCELO, I998: n²42, Im. XLIII a y b; OCAÑA, I946; MARTíNEZ NÚÑEZ, I997a: Im. I, f. I y Im. 2).

4 Se conservan dos fragmentos en el Museo de la ciudad: uno de ellos ostenta una estrella de ocho puntas y el otro una cartela epigráfica, con bordes estrellados, en cúfico austero tallado en relieve. Aunque B. Pavón dio una lectura incompleta, el texto conservado reproduce Allāh rabbu-nā ("Dios es nuestro Señor"), expresión habitualmente consignada, junto a otras, en las acuñaciones en plata de época almohade.
} 
Y es que en época almohade existieron dos variantes simultáneas de grafía cúfica (MARTíNEZ NÚÑEZ, 1997b: pp. 142-144): una, más austera y sujeta, a pesar de sus rasgos innovadores, a la tradición precedente, y otra, que gozaría de un gran desarrollo posterior, representada fundamentalmente por los llamados "motivos-tipo" (OCAÑA, 1984) y también por el cufico geométrico (OCAÑA; 1990: MARTíNEZ NÚÑNEZ, 1997b: p. 143), con quiebros, retrocesos en escuadra y complicados entrelazos en las astas, rematadas a veces con terminaciones foliadas o lobuladas, como las que ostenta la mqäbriyya malagueña del 618/1221 (OCAÑA, 1946; MARTíNEZ NÚÑNEZ, 1997a: p. 424, Im. I, f. I). El uso simultáneo de esas dos modalidades gráficas se comprueba no sólo en el caso del minarete de la Kutubiyya, que ya señalaron en su momento $\mathrm{H}$. Basset y H. Terrasse (BASSET, TERRASSE, 200I: pp. 132-134, fs. 40 a, 40 b y 46 c, 46 d), sino también en la puerta de la Qașbah de los Udāya, donde conviven los motivos-tipo con la banda epigráfica, en tres paneles, en un cúfico más austero (MARTíNEZ NÚÑEZ, 1997a: pp. 429-432, Im. 3, f. I y Im. 4). Por lo que se refiere a al-Andalus, de Jerez de la Frontera proceden dos epígrafes de cronología almohade: la lápida publicada por A. Fernández Puertas (FERNÁNDEZ PUERTAS, 1978-79: pp.228-232, Im. II), que está realizada en cúfico geométrico, mientras que el epígrafe reproducido por $\mathrm{B}$. Pavón Maldonado (véase nota 4) se incluye en la variante austera.

El resto de rasgos gráficos también responde a las características inauguradas a partir del siglo XIl. Así los grafemas I f (alif final) y 4 a (dāl aislado) presentan el típico ápice descendente por debajo de la línea de base y los trazos 9 i y m ('ayn/gayn inicial y medial), $10 \mathrm{~m}$ (fā' medial) y $16 \mathrm{f}$ (wāw final) tienen forma puntiaguda. Esos rasgos caligráficos eran desconocidos en el cúfico anterior a la etapa almorávide (OCAÑA, 194I) ${ }^{5}$, momento en el que se documentan por primera vez, para afianzarse durante el periodo almohade, hasta el punto de convertirse en características distintivas de los epígrafes cúficos desde el siglo XII en adelante. Un buen ejemplo de la fijación de estos rasgos en época almohade, entre otros muchos que se podrían aducir, lo proporciona el letrero en cúfico del conocido ataifor de Jerez de la Frontera, con decoraciones en cuerda seca y estampillado (Lám. 3). La expresión 'āfiya que reproduce, a pesar de su innovadora composición, presenta los mismos rasgos gráficos que las yeserías de Jaén: junto a las astas rectas y austeras con terminaciones a bisel, el grafema I $f$ se ha realizado con ápice descendente y el trazo 10 i en forma puntiaguda.

Sí hay que destacar que en las yeserías de Jaén esa forma puntiaguda y cerrada se extiende también al grafema 9 m, el gayn de al-Gafür, diseño poco habitual, aunque esté documentado, para esta figura en posición medial. H. Basset y $\mathrm{H}$. Terrasse señalaron que en el minarete de la Kutubiyya este trazo presenta forma abierta ${ }^{6}$, frente a la cerrada que aparecerá con posterioridad (BASSET, TERRASSE, 200 I: pp. 133-134).

Lo cierto es, sin embargo, que el grafema 9 m se realizó ya con esa forma cerrada y apuntada en el friso epigráfico de la antesala al miḥrāb en la mezquita Qarawiyyīn de Fez, de cronología almorávide (OCAÑA, 1990: p. 96, f. 7), aunque con posterioridad sea mayor su incidencia. Así se observa en algunos epígrafes andalusíes de los últimos años de dominio almorávide, como la estela funeraria del 539// I 45 (LÉVI-PROVENÇAL, I93I: n 45, pl. XII a), realizada en el muy evolucionado cúfico de Badajoz, y el epitafio de un qáiid de Ibn Mardanišs (LÉVIPROVENCAL, 1931 : pp. 99-100, n 103, pl. XXIV b), fechado en el año 566/I I 7 I. En cuanto al cúfico almohade, encontramos esa figura $9 \mathrm{~m}$ cerrada en otra estela pacense del año 556//16/ (LÉVIPROVENçAL, I931: n 48, pl. XII c), en una placa decorativa en cerámica vidriada, de proceden-

5 Esos rasgos sirvieron al autor para corregir la falsa cronología califal que se le había atribuido a la pila de abluciones del Museo de Córdoba, que es, sin duda, de época almorávide.

6 Esa misma forma abierta, para este grafema en posición medial, se observa también en las bandas epigráficas de las puertas almohades de Rabat (MARTíNEZ NÚÑ̃EZ, I997a Im. 3, f. 2) y Marrakech (ALLAIN, DEVERDUN, I957: pp. I I7-I29, fs. I4 y I5, pl. X). 
cia sevillana (TABALES, POZO, OLIVA, 1999: p. 145), o en la mqābriyya malagueña (Lám. 4) de cerámica vidriada en verde (MARTÍNEZ NÚÑEZ, 1997a: pp. 424-426, Im. 2; MARTíNEZ NÚÑEZ, 1997b: p. 143 , E 20), y después en los restos de un alfiz del Convento de Santa Clara la Real, en Murcia (NAVARRO PALAZÓN, 1995: pp. 191 - 192, fs. 125 y 126), o en las yeserías mudéjares del Palacio Episcopal de Cuenca y del Convento de Santa Clara en Toledo (PAVÓN, 1983: pp. 37I-373, E 6), hasta afianzarse en el cúfico nazarí y meriní y en el de los edificios mudéjares contemporáneos, como el Palacio de Tordesillas o el Alcázar de Sevilla, cuyos múltiples ejemplos sería prolijo detallar.

El grafema 14 f (nūn final) aparece roto, pero conserva su curvatura, casi circular, sobre el filete inferior y la impronta dejada por la prolongación final ascendente. El grafema 17 (yā') se incluye en posición aislada y final, pero en ambos casos sólo se conserva el cuerpo del grafema, lo que impide conocer cómo era su figura completa. Por lo que se refiere al trazo 3 i y m ( $\hat{y}$ imm inicial, jā' medial), presenta un diseño austero y convencional, que entronca con el de época prealmohade ${ }^{7}$, aunque ese grafema se realizó con la misma austeridad en las bandas epigráficas de la puertas monumentales de Marruecos, e incluso en los motivos-tipo de la puerta de la Qașbah de los Udāya (MARTíNEZ NúÑEZ, 1997a: Ims. 3 y 4), y en algunos ejemplares andalusíes de cronología almohade más tardía: la mqābriyya almeriense, datada en la segunda mitad del siglo VI H. (OCAÑA, 1964: p. 102, n 106) - la estela del 623/1226, de la misma procedencia (OCAÑA, 1964: p. 106, n I 10), así como en algunas inscripciones de Valencia (BARCELÓ, 1998:, pp. 203-204, n44).

Se puede afirmar, pues, que los rasgos gráficos de las yeserías de Jaén son almohades, aunque integren, junto a las innovaciones propias de ese periodo, ciertos elementos de la tradición anterior, que se mantuvieron en época almohade, incluso tardía, como demuestran los ejemplares de Almería y Valencia.

\section{LOS ELEMENTOS DECORATIVOS}

El diseño austero de los grafemas que componen esta inscripción se ve compensado por la inclusión de una serie de motivos ornamentales para rellenar los vacíos dejados entre las astas. Entre esos motivos predominan grandes palmetas lisas, dobles o simples, con terminaciones enroscadas en espiral, que arrancan, a veces, de la misma línea de base de escritura, como ocurre en la expresión bi-mujrầīn y al comienzo del término 'ibādĩ. Junto a las palmetas, se incluyen pequeños goterones y otros ornatos vegetales, como el pimiento que aparece en el segundo fragmento.

El mismo programa ornamental, inserto entre los elementos gráficos y dejando ver el fondo desnudo por el que discurren los caracteres, se encuentra en epígrafes almohades realizados sobre materiales y soportes diversos: madera, piedra o cerámica, como la inscripción de un dintel de madera de Fez (JAÉN, 1995: p. 186, n 191) y las bandas epigráficas de la Bāb al-Ruwāh y de la puerta de la Qașbah de los Udāya de Rabat (CAILlÉ, 1949: pp. 96-100, E 25 y pp. I39- |44, f. 45; MARTÍNEZ NÚÑ̃EZ, 1997a: p. 432), así como en la Bāb Agnaw de Marrakech (Lám. 5) (ALLAIN, DEVERDUN, 1957: pp. 83-126, fs. 14 y 15, pl. $X)$. Puede comprobarse, asimismo, su presencia en ejemplares andalusíes de cronología almohade: en un brocal de cerámica procedente de Córdoba (JAÉN, 1995: p. 127, n 75), fechado en la segunda mitad del siglo XII -las palmetas dobles arrancan, como en Jaén, de la línea de base (Lám. 6)-, en la mqābriyya de Játiva (FERNANDEZ PUERTAS, 1978-79: E I), igual que en otras levantinas (BARCELÓ, 1998: $n^{\circ}$ 44, f. I 2, I m. XLV a y b), y en las mqābriyyas malagueñas: la de mármol del año 618/1221 y la de cerámica vidriada en verde, anteriormente citadas, aunque estas últimas presentan una mayor profusión decorativa.

Las grandes palmas simples o dobles, lisas, como en este caso, o con digitaciones, los goterones y las estilizaciones vegetales y florales,

\footnotetext{
${ }^{7}$ Lo habitual en el cúfico almohade es que este grafema presente un diseño muy evolucionado, que se mantendrá en la etapa nazarí y meriní, como se observa en los motivos-tipo de Tinmal o en la máabriyya de Játiva y en la lápida de Jerez de la Frontera (OCAÑA, 1984: pp. 160-1 68; OCAÑA, 1990: pp. 98- I00, fs. 9 y 12; FERNÁNDEZ PUERTAS, 1978-79: pp. 226 y 230, fs. 2 y 4).
} 
como las piñas o los típicos pimientos, constituyen motivos ornamentales asiduos en el programa decorativo almohade, aunque algunos de ellos, sin duda, se inserten en la tradición anterior, y se documentan ya en las primeras construcciones de la dinastía mu'miní, como se aprecia en los motivos-tipo de la mezquita de Tinmal (OCAÑA, 1990: f. 9) y especialmente en la decoración exterior del minarete de la Kutubiyya (BASSET, TERRASSE, 200I: fs. 39, 49, 52 d, $54,60 \circ 61)$.

Por otra parte, y como mencioné al principio, la banda epigráfica aparece asociada a otros fragmentos de yeserías: paneles de ataurique (Láms. 7 y 8) con enmarques de lacería y dovelas alternas, lisas y con decoración de ataurique (Láms. 9 y I0), pertenecientes a una puerta de doble arco.

El ataurique se compone fundamentalmente de palmetas con dos digitaciones o foliolos entre anillos o círculos, realizados estos últimos con la forma del grafema 16 a (wāw aislado); tipo específico de digitación y característico de las yeserías almohades (OCAÑA, 1990: pp. 103-105, fs. 18 y 19). Aunque la palmeta digitada entre anillos se documenta ya en la Qubba almorávide de Marrakech (CHIAUZZI et alü, 1991: fs. 70 y 71) O en las yeserías murcianas de cronología mardaniší ${ }^{8}$, en opinión de M. Ocaña, "el tipo más avanzado de palmeta digitada almorávide es aquél en el que los foliolos o digitaciones se presentan repartidos en' grupos por medio de unos anillos u ojetes, variando, a capricho del tallista, la cantidad de foliolos que entran en cada grupo de una misma hoja o palmeta. Por el contrario, en la auténtica palmeta digitada de la época de los Unitarios, los foliolos siempre aparecen agrupados por parejas $y$, lo que es infinitamente significativo, al ani-
Ilo separador se le da la configuración de la traza cúfica 16 a" 9 (OCAÑA, 1990: p. 103).

A partir de ese elemento básico, la palmeta de doble digitación con anillo intercalado, se conforman los motivos ornamentales que componen el ataurique, con una gran variedad de formas vegetales y florales, palmas dobles, enroscadas en espiral y palmas simples; motivos todos ellos que se incluyen, con digitaciones o sin ellas, en el repertorio decorativo almohade, como en el caso del minarete de la Kutubiyya (BASSET,TERRASSE, 200 I: fs. 54 y $6 \mathrm{l}$ ), o las albanegas de las puertas monumentales (CAILLÉ, 1949: fs. I6- 18 y 43,44$)$.

Especialmente abundante es, asimismo, en época almohade el uso del entrelazo como elemento decorativo, hasta el punto de constituir, como afirman H. Basset y H.Terrase (2001: pp. 90 y 98), el motivo primordial de la ornamentación del mihrāa de la "primera Kutubiyya", según la denominación de estos autores, o del mihrāb de la mezquita de Tinmal (MARTíNEZ NÚÑ̃̃EZ, 1997b: p. 143, f 16).

En uno de los fragmentos (Lám. 8) se aprecia el arranque de una composición decorativa de larga tradición en el mundo islámico, el denominado "árbol de la vida". También cuenta con una larga tradición la alternancia de dovelas lisas y decoradas en ataurique, que en al-Andalus se remonta a las manifestaciones arquitectónicas más antiguas, como la Puerta de San Esteban de la Mezquita de Córdoba, afianzándose en época califal omeya, con las múltiples muestras de Córdoba y de Madīnat al-Zahrā'. Con posterioridad, se mantuvo en época taifa ${ }^{10}$ y almorávide hasta las etapas más tardías, por ejemplo en las construcciones murcianas atribuidas a la etapa mardaniší "I, en algunas dependen-

8 Como las del Castillejo de Monteagudo, el Palacio de Pinohermoso y la Dār al-șugrà de Santa Clara la Real (NAVARRO, JIMÉNEZ, 1995a: fs. 39, 42, 43 y 46).

9 Para M. Ocaña, ese tipo de digitación venía a representar el lema esencial de los unitarios: Alláh wanda-hu.

I0 Como especialmente representativos se pueden citar el arco del mitiráb de la Áljafería de Zaragoza (MARTíNEZ NÚÑ̃EZ, I99b: E. 8) o los del siglo XI conservados en la Alcazaba de Málaga (TORRES BALBÁS, I960: PP. 4I-43).

I I Como el arco de acceso al salón norte del Palacio de Pinohermoso (NAVARRO, JIMÉNEZ, 1995b: E. 10) y el de Monteagudo (NAVARRO, JIMÉNEZ, 1995a: f. 43). 
cias de la Alhambra y del Alcázar de Pedro I en Sevilla ${ }^{12}$. Por lo que respecta al Magreb, se pueden citar como ejemplo de la presencia de esa tradición, los arcos de la sala de acceso al mihrāb de la mezquita de Tremecén (CHIAUZZI et alii, | 99 |: f. 77), edificio terminado en | | 36. Sin embargo, es preciso consignar que esa forma tradicional de exornar los arcos no es la habitual en los edificios almohades que se nos han conservado. En palabras de L. Torres Balbás, "ninguna arquitectura occidental descompuso y deformó el arco tanto como la almohade", aunque el mismo autor afirme que en los mihräb/s se fingía siempre un arco de herradura adovelado, siguiendo las normas tradicionales (TORRES BALBÁS, 1949: p. 12). Pero en los mihrāb/s esas dovelas son únicamente lisas, como lo son también las que se simularon en el arco angrelado de la Báb Agnaw de Marrakech (Fig I I).

En resumen, y como en el caso de los rasgos gráficos, los restantes motivos decorativos remiten también a una cronología almohade, aunque estén presentes elementos de etapas precedentes y algunos de ellos con una larga tradición anterior.

\section{EL CONTENIDO DE LA INSCRIPCIÓN}

Si los aspectos hasta aquí analizados inducen, en su conjunto, a fechar las yeserías de Jaén en época almohade, esa adscripción cronológica se ve reforzada por el carácter del texto y por los versículos coránicos que reproduce.

Lo primero que se debe señalar es que, en contraste con lo que sucedía en etapas precedentes, cuando las citas coránicas se reservaban a los epígrafes fundacionales de mezquitas (MARTÍNEZ NÚÑEZ, 200 I: p. 413) y a los epitafios ${ }^{13}$, en época almohade el uso del Corán se exiende a todo tipo de inscripciones. Los almohades dotaron a la epigrafía árabe de una presencia, monumentalidad y relieve, en tanto que elemento de decoración arquitectónica, de la que carecía hasta ese momento, pero, al mismo tiempo, renunciaron al tradicional formulario fundacional y propiciatorio para el soberano, otorgando a sus escritos epigráficos un contenido exclusivamente religioso (MARTíNEZ NÚÑ̃EZ, 1997a: pp. 434-444). Un buen ejemplo del contraste con la etapa inmediatamente anterior lo proporciona la inscripción soberana, en grafía cursiva, a nombre del Amìr al-musliminn 'Alī ibn Yūsuf, en la Qubba almorávide de Marrakech (DEVERDUN, 1956: p. 27, $n^{\circ} 28$ ), que fue martilleada por los almohades tras la toma de Marrakech en II47.

Estos textos almohades solían empezar con fórmulas introductorias fijas: ta'awwud, basmala completa y tașliya, a las que seguían las citas coránicas, convertidas ahora en la parte fundamental del contenido, como se puede comprobar en las inscripciones de los miţrāb/s de la Kutubiyya y de la mezquita de la Qașbah de Marrakech, pero también en las de las puertas monumentales (MARTíNEZ NÚÑ̃EZ, 1997a: pp. 437-439).

Y eso es lo que sucede en las yeserías de Jaén. Los fragmentos que se nos han conservado reproducen el final de Q. XV, 48 y la aleya siguiente entera ( $Q . X V, 49)$, por lo que, indudablemente, el texto tenía que ser más largo y hubo de incluir, para que tuviera sentido el fragmento coránico elegido, los versículos precedentes de la misma sūra. Como mínimo tenía que consignar también $\mathrm{Q}$. XV, 46-47 y la parte perdida de la aleya 48 , posiblemente precedidos de las citadas fórmulas introductorias.

Los versículos 46-49 de la azora XV -denominada sūrat al-hiy̌r, en alusión a la salida del

\footnotetext{
12 En la Alhambra suelen ser sólo dovelas de ataurique, como en el arco angrelado del oratorio del Mexuar o en los dinteles de la puerta de acceso al Mexuar y de la fachada de Comares (TORRES BALBÁS, 1949: fs. 79, 80 y 83). De la Madraza granadina se conserva un dintel en el que alternan dovelas lisas y de ataurique (LEVI-PROVENCAL, 193I: $n^{\circ}$ I72, pl. XXXVIII F). En el Salón de Embajadores del Alcázar de Sevilla los arcos de herradura alternan dovelas lisas y decoradas con ataurique, en la más pura tradición califal (TORRES BALBÁS, 1949: f 357).

13 La excepción la proporciona la epigrafía de la taifa hudi, como demuestran las inscripciones de la Aljafería de Zaragoza (CABAÑE-
} RO, LASA, 1998). 
Profeta de La Meca y a su llegada a Medina- se refieren a la entrada de los creyentes, temerosos de Dios, en el paraíso donde estarán entre fuentes y jardines (Q. XV, 45) y dicen así: (46) Udjulū-hā bi-salām āminīn (47) wanaza'nā mā fi sudūri-him min gill ijwānan 'alà surur mutaqābilīn (48) Ià yamassu-hum fi-hā nașab wa-mā hum min-ha bi-mujraŷin (49) nabbi' 'ibādì annì Ana al-Gafür al-Rahìm ("Entrad en ellos en paz, seguros / Habremos arrancado el odio que haya podido haber en sus pechos. Serán como hermanos, en lechos, unos enfrente de otros / Allí no sufrirán pena, ni serán expulsados / Informa a Mis siervos de que Yo soy el Indulgente, el Misericordioso").

Pues bien, lo más destacable, con respecto a estos versículos coránicos, es que no aparecen consignados en los epigrafes árabes del Occidente islámico, salvo en las inscripciones monumentales de la dinastía mu'miní. Es muy significativo el hecho de que las aleyas 46-48 de la súra XV del Corán sólo se encuentren reproducidas en la banda epigráfica de la Bāb Agnaw de Marrakech, construida por orden del califa Ya'qūb al-Manșūr en el año 584// I 88 (DEVERDUN, 1956: pp. 49-50; MARTÍNEZ NÚÑ̃ZZ, 1997a: pp. 432 y 437-438), $y$ en un dintel de madera procedente de Fez (JAÉN, 1995: p. 186), anteriormente citado por la semejanza que guarda su cúfico, y los motivos ornamentales que lo acompañan, con los de las yeserías de Jaén ${ }^{14}$. Aparte de la decoración parietal, esas aleyas se reproducen también en uno de los aldabones de la Puerta del Perdón sevillana, en grafía cursiva.

Con posterioridad a la etapa almohade se reprodujeron los versículos 46-47 de la sCira $\mathrm{XV}$ en la inscripción de la puerta de entrada a la mezquita de Lalla al-Zahr en Fez, de cronología meriní ${ }^{15}$. A eso hay que añadir que, también en época meriní, esta cita coránica se ponía en relación con las prácticas sufíes y con quienes habitaban en zawiyas (IBN MARZUQ,
1977: p. 340). Pero, si en el caso meriní es la puerta de una mezquita la que constata el uso de ese fragmento coránico en epigrafía, los almohades lo reproducen en la puerta monumental de la capital Marrakech y en el acceso a una zona residencial de la alcazaba de Jaén.

Como ya señalé en referencia a la Bāb Agnaw (MARTíNEZ NÚÑ̃EZ, 1997a: p. 437), es innegable la adecuación de este texto coránico al soporte y al lugar en el que se ubica, así como a la función simbólica que a estos últimos se les asignaba. Lo mismo sucede en la puerta de la Qașbah de los Udāya, cuyo epígrafe reproduce Q. LXI, I I- I3, de un contenido similar, sobre la introducción de los creyentes, que combaten en la senda de Dios, en el paraíso, con sus ríos y jardines (MARTíNEZ NÚÑEZZ, 1997a: pp. 429 y 438). Resulta evidente, en estos casos, la equiparación entre la entrada al paraíso, que se menciona en los textos coránicos de las puertas, y la entrada a las dependencias almohades $y$, lo que considero más importante, la identificación de la capital Marrakech y de las construcciones almohades en la Qasbah de Rabat y en el castillo de Jaén con el paraíso coránico, con sus moradas, fuentes y jardines; una imagen muy habitual en el urbanismo islámico, pero explícitamente puesta de manifiesto en época almohade, como nunca antes se había hecho, mediante la epigrafía monumental.

Por consiguiente, es el contenido de la inscripción el que con mayor rotundidad permite otorgar a estas yeserías una cronología almohade. Aunque, si se pretende afinar más la cronología, es preciso señalar que el control de los almohades sobre la ciudad de Jaén no fue empresa fácil, como sucedió en otros territorios de al-Andalus.

Los almohades se apoderaron de Jaén en el año | | 48, tras la rebelión antialmorávide y la breve etapa de dominio de Abū Ya'far Ahmmad

14 Aunque en el Catálogo de la exposición de Jaén se afirma que el fragmento coránico es Q. XI, 47, se trata, sin ninguna duda, de Q. XV, 47.

15 Dato extraído de la tesis doctoral de Aouni Lhaj Moussa, Étude des inscriptions merinides de Fas, realizada bajo la dirección de Solange Ory y leída en febrero de 1991 en la Universidad de Provence. Agradezco a su autor el que me facilitara un ejemplar de su tesis, aún inédita. 
ibn Hūd y de Ibn Gāniya (AGUIRRE, JIMÉNEZ MATA, 1979: pp. 208-2।0). Pero en el año I 59 el gobernador almohade de Jaén, Muhammad ibn 'Alī al-Kumī, entregó la ciudad a Ibn Mardanǐš, señor de Murcia, y a su lugarteniente y suegro Ibn Hamušk. Este último se estableció en Jaén y colaboró con su yerno, hostigando otras ciudades bajo dominio almohade, hasta que en el año I 169 rompió las relaciones con Ibn Mardanī̌s y aceptó el tawhīid. Ibn Hamušk gobierna desde entonces la ciudad en nombre del califa almohade, hasta el punto de tener que soportar ahora los ataques de su antiguo aliado, viéndose obligado a pedir ayuda al califa, con cuyo ejército colaboró en el ataque a los mardanī̌síes de | |7|. A partir de ese año Jaén estuvo sometida al dominio almohade, hasta 1229, cuando vuelve a caer en poder de los Banū Hūd y más tarde de los Banū I-Aḥmar (AGUIRRE, JIMÉNEZ MATA, 1979: pp. 213-215 y 237-240).

Así, pues, Jaén estuvo bajo control almohade en dos periodos: el primero entre los años | | 48 y | | 59 y el segundo entre | 169 y 1229 , incluyendo la etapa en que lbn Hamull< prestó obediencia al califa almohade.

Por otra parte, y como señala J. C. Castillo Armenteros, fue entre los siglos XII y XIII, con Jaén situada en territorio de frontera y sometida a la presión de los ejércitos cristianos, cuando se realizaron en la alcazaba de la ciudad las mayores transformaciones: reforma de las murallas, construcción de nuevas viviendas y conversión de la primitiva alcazaba en zona residencial (CASTILLO ARMENTEROS, 1995: pp. 78-79); unas transformaciones que, como es lógico suponer, se realizarían por iniciativa y a cargo del poder central, a través de sus gobernadores-representantes o de la autoridad a la que permitían asumir el gobierno de la ciudad. De hecho, el material cerámico, que apareció asociado a las yeserías, es en su mayor parte también de cronología almohade.
No obstante, resulta muy difícil precisar a cuál de los dos periodos pueden adscribirse las yeserías: del primero de ellos se conoce la existencia del sayyid, o gobernador, de los Kumya, el mismo clan almohade de los propios califas mu'miníes, que bien pudo llevar a cabo la transformación de la alcazaba. Pero también pudo construirse esta zona residencial, y las yeserías que la decoraban, durante el segundo periodo y no hay que descartar la posibilidad de que esto sucediese en la etapa de Ibn Hamušk, a partir del momento en que aceptó el tawhīd. Esta segunda hipótesis resulta, desde mi punto de vista, más admisible, pues, entre otros motivos, explicaría el hecho de que en estas yeserías se incluyan - junto a los numerosos rasgos puramente almohades, especialmente el texto coránico reproducido- elementos de la tradición andalusí y almorávide anterior ${ }^{16}$, algunos de los cuales no suelen estar presentes en la decoración de las construcciones del califato mu'miní, como es el caso de los arcos con alternancia de dovelas lisas y decoradas en ataurique.

Lo cierto es que estos hallazgos de Jaén proporcionan una de las escasas muestras que poseemos de la decoración existente en la arquitectura residencial almohade y vienen a ampliar y completar el panorama que, sobre ornamentación en arquitectura doméstica, suministran las viviendas de Siyāsa, en Murcia (NAVARRO, JIMÉNEZ, 1995c). Y no es menor su importancia en el terreno epígrafico: la inscripción, aquí analizada, constituye el único ejemplar de estas características procedente de Jaén, ya que, hasta ahora, sólo se conocían, para el periodo almohade de esta ciudad, dos epígrafes funerarios, uno realizado en grafía cursiva, con la típica labra incisa de la zona, y fechado en el año 549/ I I 54 (LEVI-PROVENCAL, 193 I: n 156, pl. XXXIII c; LABARTA, 1990: n 17), y otro, en cúfico tallado en relieve, del año 575/II79 (LEVI-PROVENCAL, 1931: n 157; PAVÓN, 1984: p. 336, Ims. II a, b y c; LABARTA, 1990: $n^{\circ}$ 18) ${ }^{17}$.

\footnotetext{
16 L Torres Balbás hablaba de dos tendencias en la decoración arquitectónica almohade y una de ellas, la de mayor profusión ornamental, la atribuía a "la tradición hispano-almorávide" (TORRES BALBÁS, 1949: p. 48).

17 A ellos hay.que añadir una estela de siglo XII, procedente de Ibros, cuyo contenido es coránico y está realizado en cúfico, también de labra incisa (LABARTA, 1990: $\left.n^{\circ} 19\right)$.
} 


\section{BIBLIOGRAFÍA}

AGUIRRE SÁDABA, J.; JIMÉNEZ MATA, Ma C. (1979): Introducción al Jaén islámico (estudios geográfico-histórico). Jaén.

ALLAIN, C.; DEVERDUN, G. (1957): "Les portes anciennes de Marrakech", Hespéris. XLIV, pp. 55- 126.

BARCELÓ, C. (1998): La escritura árabe en el país valenciano. Inscripciones monumentales. Valencia.

BASSET, H.; TERRASSE, hl. (200I): Sanctuaires et forteresses almohades. París. (Nouvelle édition, Maisonneuve et Larosse).

CABAÑERO SUBIZA, B.; LASA GRACIA, C. (1998): "La epigrafía del palacio hudî”, La Aljafería, vol. II. Zaragoza, pp. 373-389.

CAILLÉ, J. (1949): La ville de Rabat jusqu'au Protectorat francais. I. Histoire et archéologie. París.

CASTILLO ARMENTEROS, J. C. (1995): "Las fortificaciones del Cerro de Santa Catalina (Jaén)", El zoco. Vida económica y artes tradicionales en al-Andalus y Marruecos. Barcelona, pp. 77-85.

CHIAUZZI, G.; GABRIELI, F.; GUICHARD, P.; GOLVIN, I.; SARNELLI CERQUA, C. (199|): Maghreb médiéval. L'apogée de la civilisation islamique dans l'Occident Grabe. Aix-en-Provence.

DEVERDUN, G. ( I 956): Les inscriptions arabes de Marrakech. Rabat.

FERNÁNDEZ PUERTAS, A. (1978-79): “Dos lápidas almohades. Micrábriya de látiva y lápida de la cerca de Jerez de la Frontera", Miscelánea de Estudios Árabes y Hebráicos. XXVII-XXVIII, I, pp. 223-232.

IBN MARZUQ (1977): El Musnad: hechos memorables de Abü l-Hasan, sultán de los benimerines. Estudio, traducción, anotación e índices anotados por Ma J.Viguera. Madrid.

JAÉN (1995): El zoco. Vida económica y artes tradicionales en al-Andalus y Marruecos. Barcelona. Catálogo Exposición.

LABARTA, A. (1990): "Las lápidas árabes de la provincia de Jaén", Homenaje a Manuel Ocaña Jiménez. Córdoba, pp. |23-137.

LABARTA, A.; BARCELÓ, C. (1992): "Miscelánea epigráfica", Al-Qantara. XIII, 2, pp. 537-559.

LÉVI-PROVENCAL, E. (193 I ): Inscriptons arabes d'Espagne. París- Leiden.

MARTíNEZ NÚÑEZ, Ma A. ( I 997a): "Epigrafía y propaganda almohades", Al-Qantara. XVIII, 2, pp. 4I5-445.

MARTÍNEZ NÚÑEZ, Ma A. ( I 997b): "Escritura árabe ornamental y epigrafía andalusi", Arqueología y Territorio Medieval. 4, pp. 127-162.
MARTÍNEZ NúÑ̃EZ, Ma A. (200l): "Sentido de la epigrafía omeya de al-Andalus", Ma. J.Viguera Molins; C. Castillo (coords.): El esplendor de los omeyas cordobeses. La civilización musulmana en Europa Occidental, vol. Estudios. Granada, pp. 408-417.

NAVARRO PALAZÓN, J. (1995): "Un palacio protonazarí en la Murcia del siglo XIIl: al-Qasr al-sagir", J. Navarro Palazón (ed.): Casas y palacios de al-Andalus. Barcelona pp. 177-205.

NAVARRO PALAZÓN, J.; JIMÉNEZ CASTILLO, P. (1995a): "El Castillejo de Monteagudo: Qasr ibn Sacd", Navarro Palazón (ed.): Casas y palacios de al-Andalus, pp. 63-I05.

NAVARRO PALAZÓN, l.; JIMÉNEZ CASTILLO, P. ( 1995b): "Casas y palacios de al-Andalus. Siglos XII y XIII", Navarro Palazón (ed.): Casas y palacios de al-Andalus, pp. 17-32.

NAVARRO PALAZÓN, J.; JIMÉNEZ CASTILLO, P. ( I 995c): "La decoración almohade en la arquitectura doméstica: la casa n 10 de Slyása", Navarro Palazón (ed.): Casas y palacios de al-Andalus, pp. I 17-137.

OCAÑA JIMÉNEZ, M. (194I): "La pila de abluciones del Museo de Córdoba”, Al-Andalus. VI, pp. 446-456.

OCAÑA JIMÉNEZ, M. (1946): "Una mqábriyya almohade malagueña de 1221 J.C.", Al-Andalus. XI, pp. 224-230.

OCAÑA JIMÉNEZ, M. (1964): Repertorio de las inscripciones árabes de Almería. Madrid, Granada.

OCAÑA JIMÉNEZ, M. (1984): "Cúpulas de la mezquita de Tinmal: las inscripciones de sus celosías", C. Ewert y J. Wishak: Forschunden zur almohadischen Moschee. Lieferuns 2. Die Moschee von Tinmal (Marocco). Madrider Beitráge, pp. $160-168$

OCAÑA JIMÉNEZ, M. (1990): "Panorama sobre el arte almohade en España", Cuadernos de la Alhambra. 26, pp. $9|-|||$.

PAVÓN MALDONADO, B. (1981): Jerez de la Frontera. Arte islámico y mudéjar. Madrid.

PAVÓN MALDONADO, B. (1983): "Arte islámico y mudéjar en Cuenca”, Al-Qantara. IV, pp. 357-376.

PAVÓN MALDONADO, B. (1984):"Jaén medieval. Arte y arqueología árabe y mudéjar", Al-Qantara. V, pp. 329-366.

TABALES RODRÍGUEZ, M. A.; POZO BLÁZQUEZ, F; OLIVA ALONSO, D. (1999): "El edificio almohade bajo el palacio de Conde de Ibarra I 8", M.Valor Piechota y A. Tahiri (coords.): Sevilla Almohade. Sevilla-Rabat, pp. I43- 146.

TORRES BALBÁS, L. (1949): Arte almohade. Arte nazad Arte mudéjar. Ars Hispaniae, vol. IV. Madrid.

TORRES BALBÁS, L. (1960): La Alcazaba y la Catedral de Málaga. Los monumentos cardinales de España, XXIV. Madrid. 


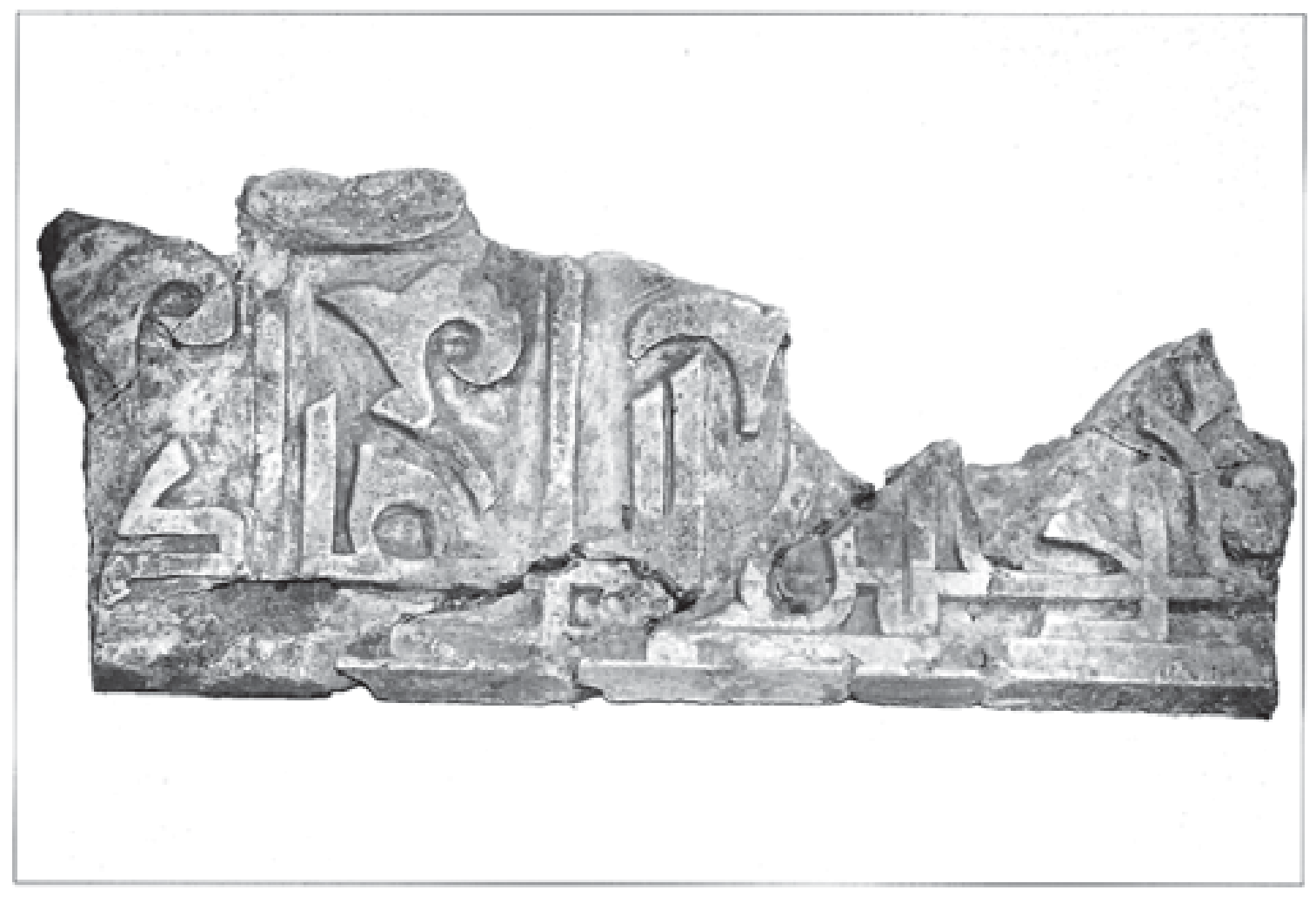

Lámina I. Primer frogmento de la inscripción

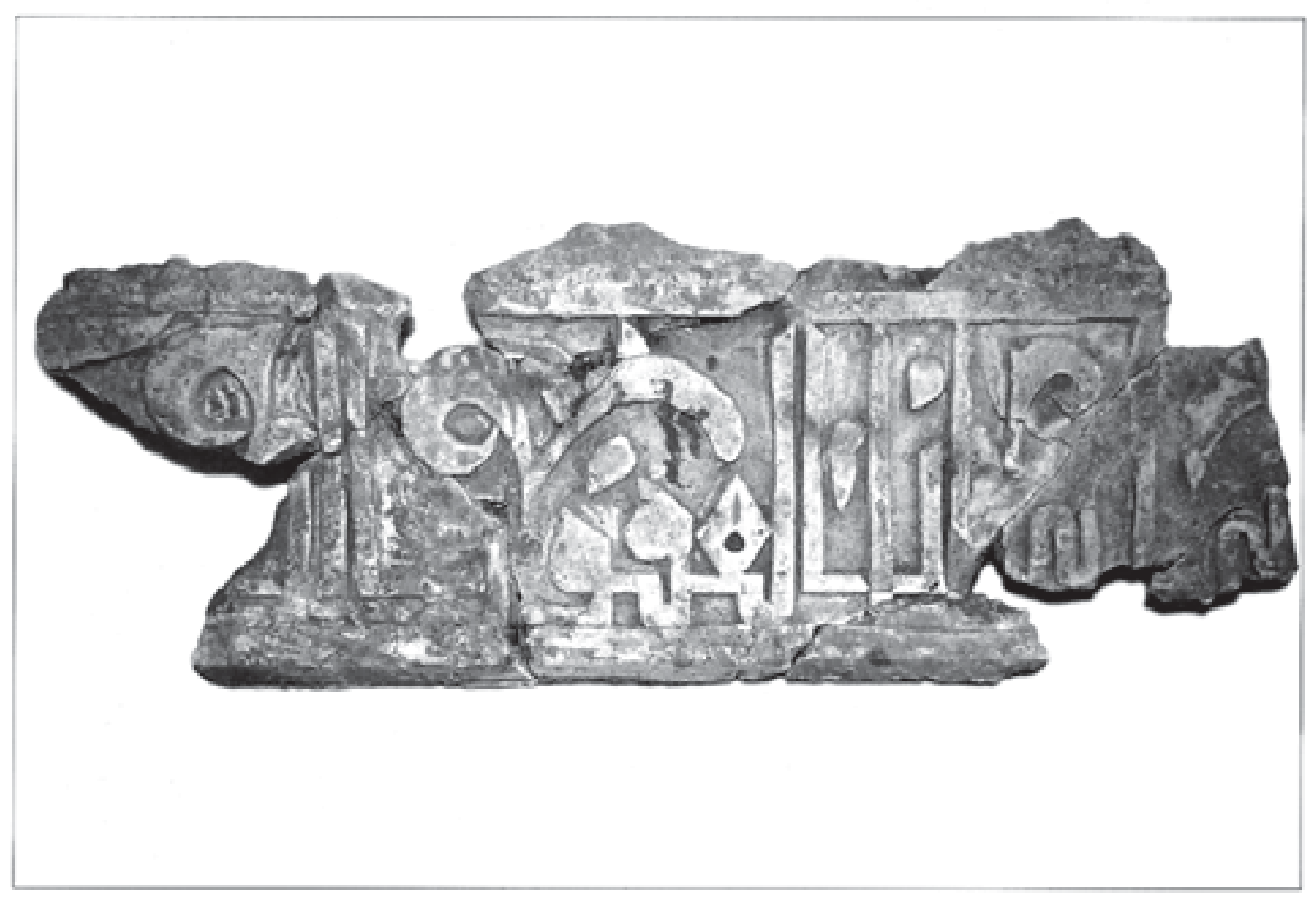

Lámina 2. Segundo fragmento de la inscripción 


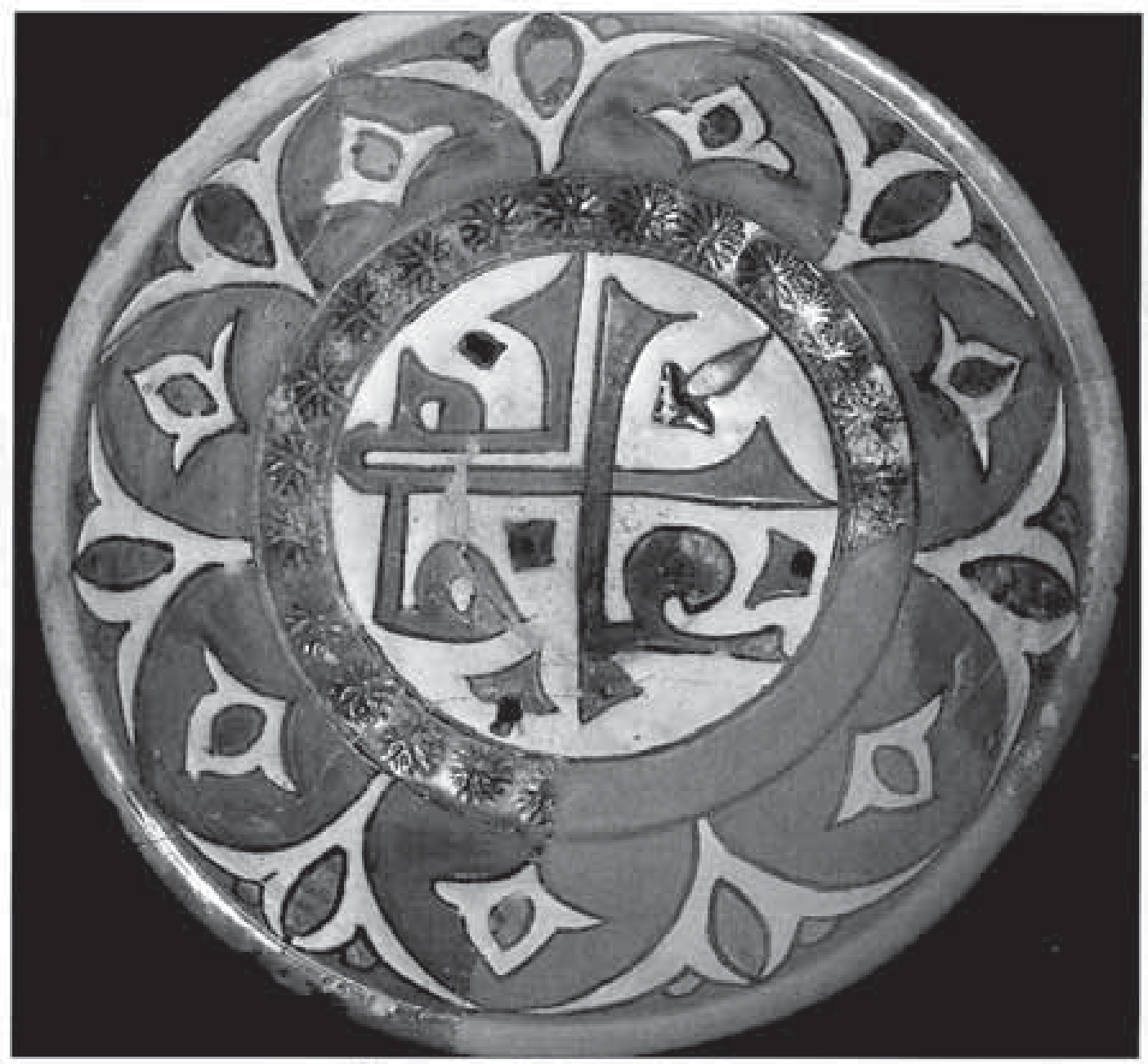

Lamina 3. Ataifor de jencz de la Frontera

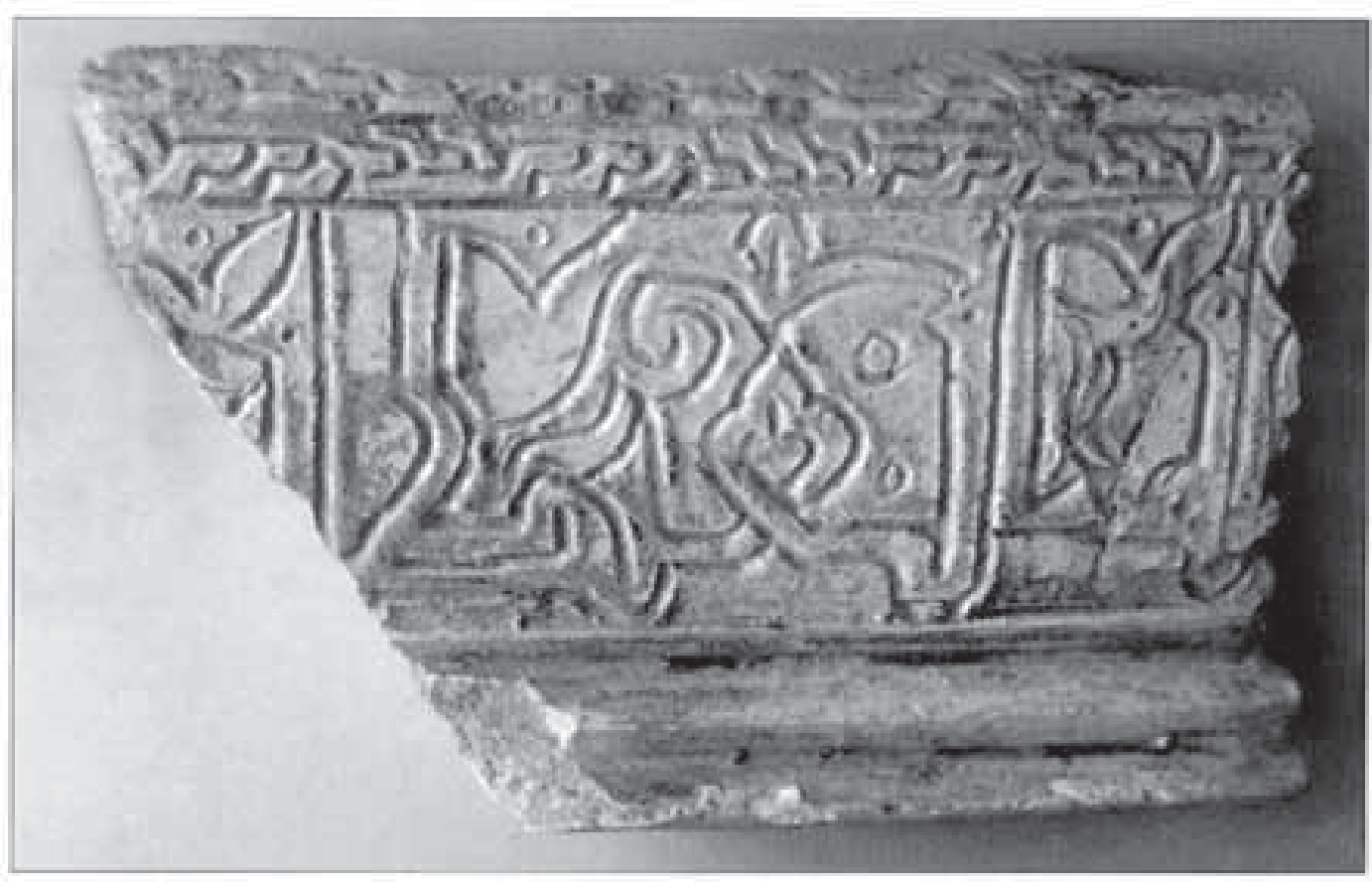

Lámina 4. Masabrinya de cerómica (Málago) 


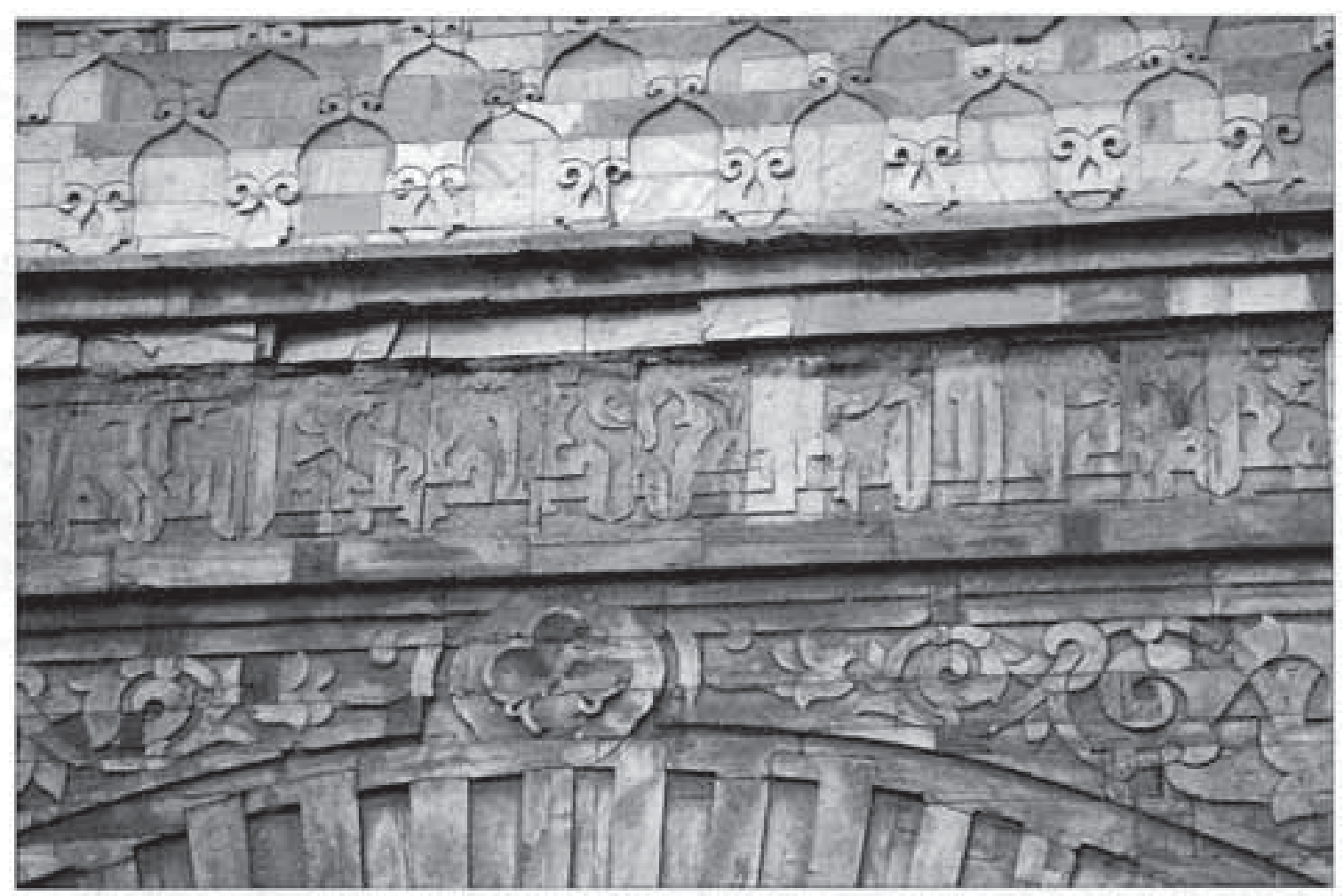

Lámina 5. Banda epigrúfica

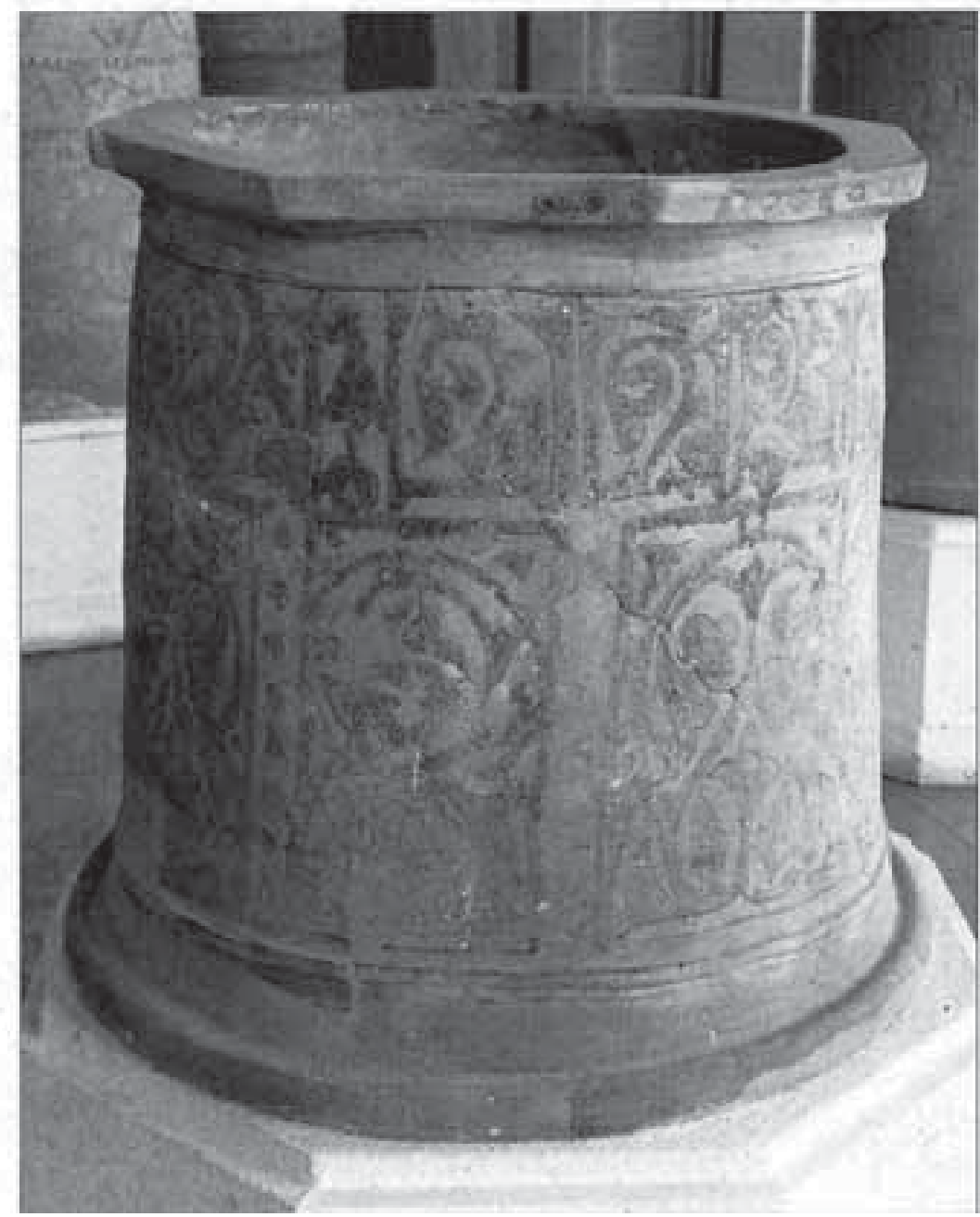

de la B.ib Agnaw (Marrokech)

Lámina 6. Brocal de pozo

del Museo de Córdoba 


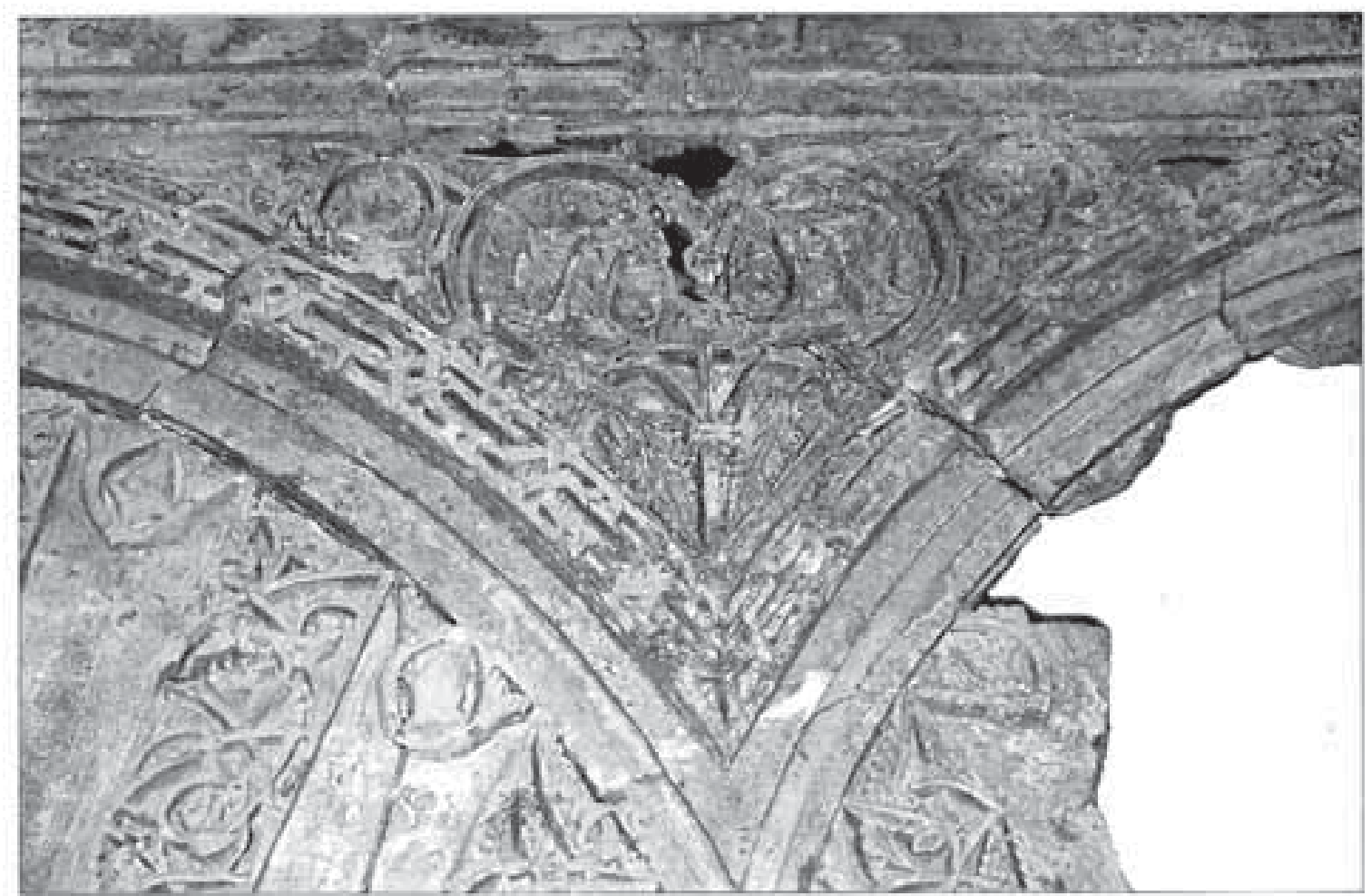

Lámina 7. Parel de ataurique

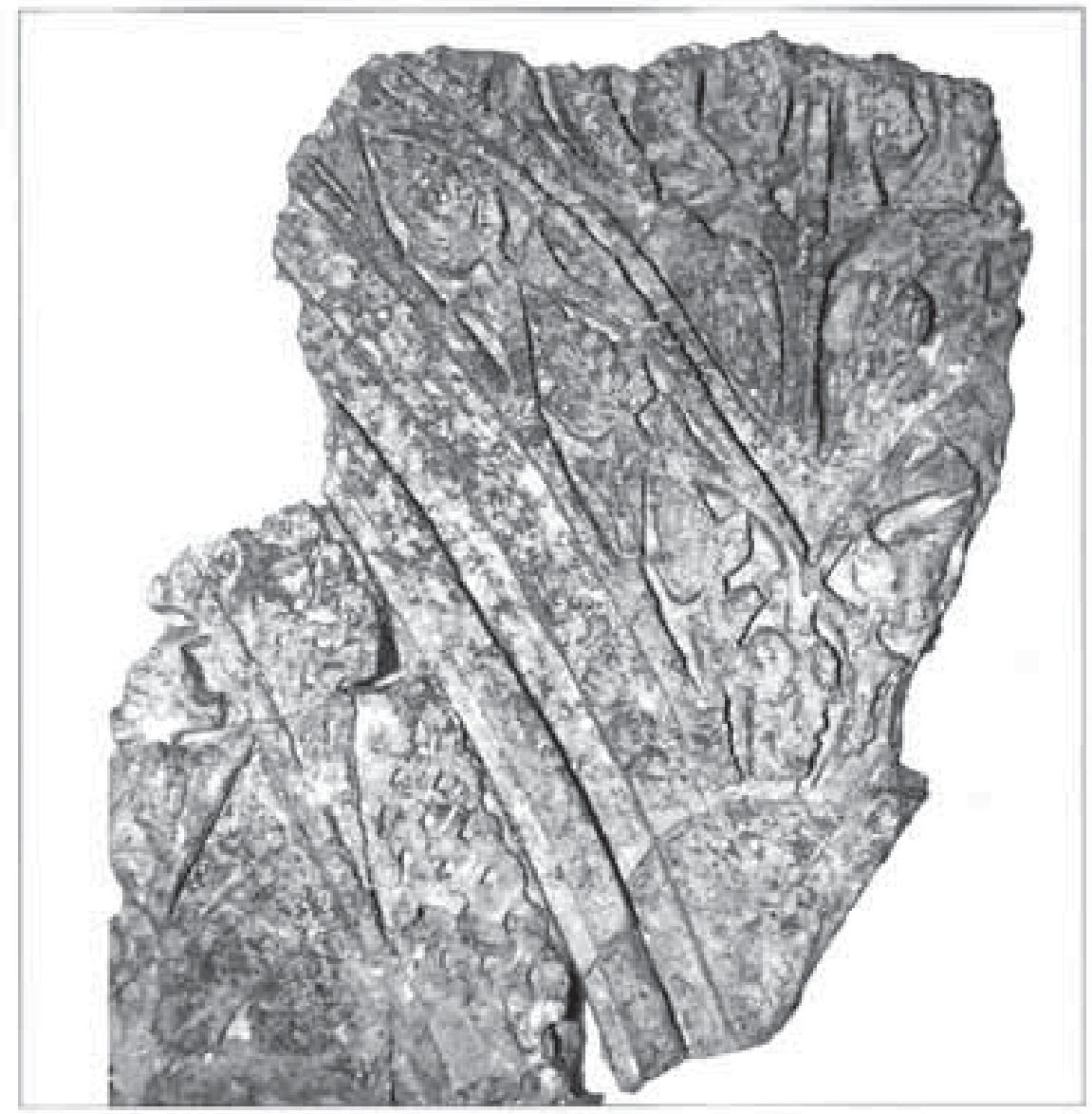

Lámino 8. Panel de ataunique 


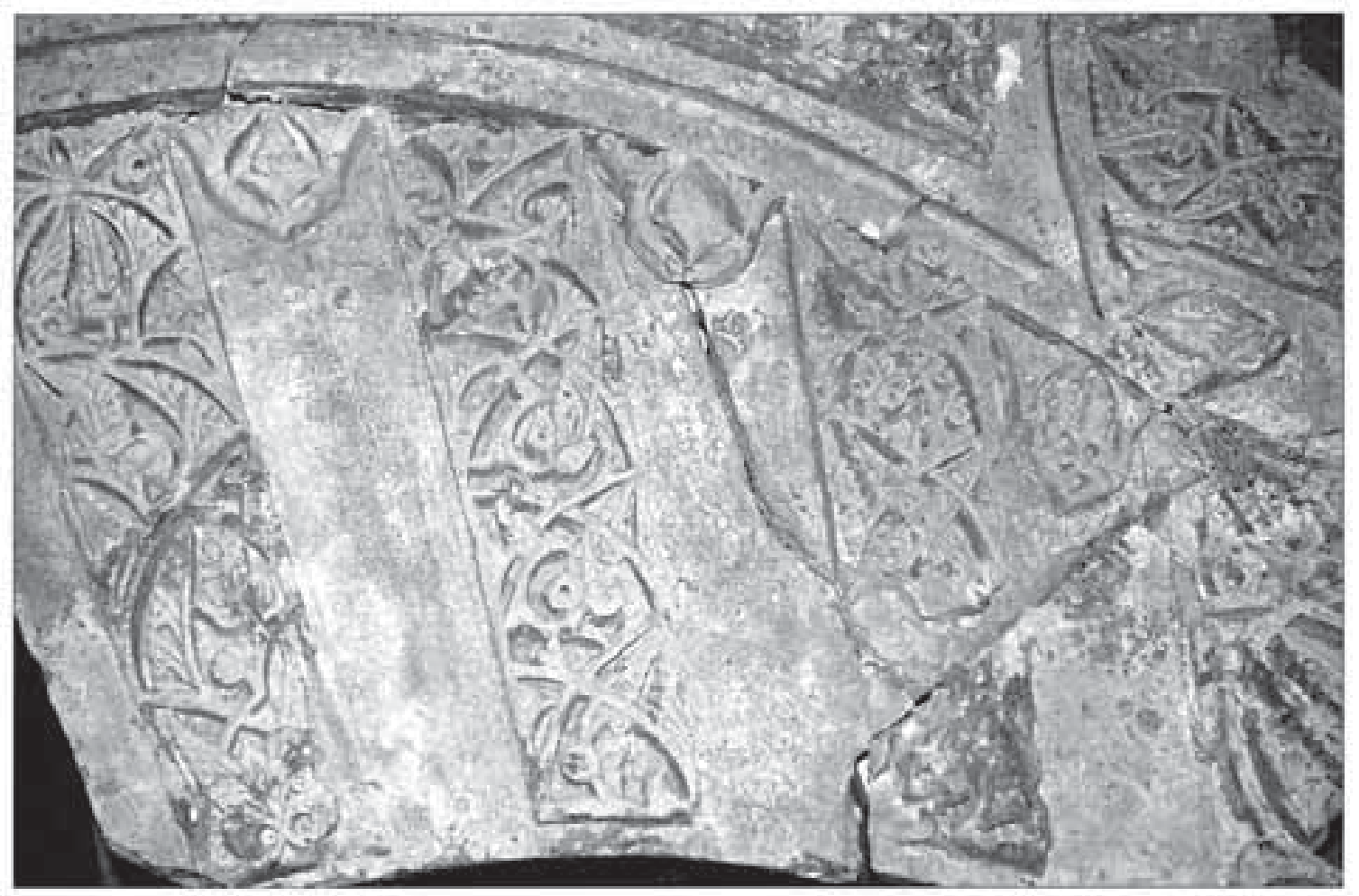

Lámina 9. Doveías de los arcos

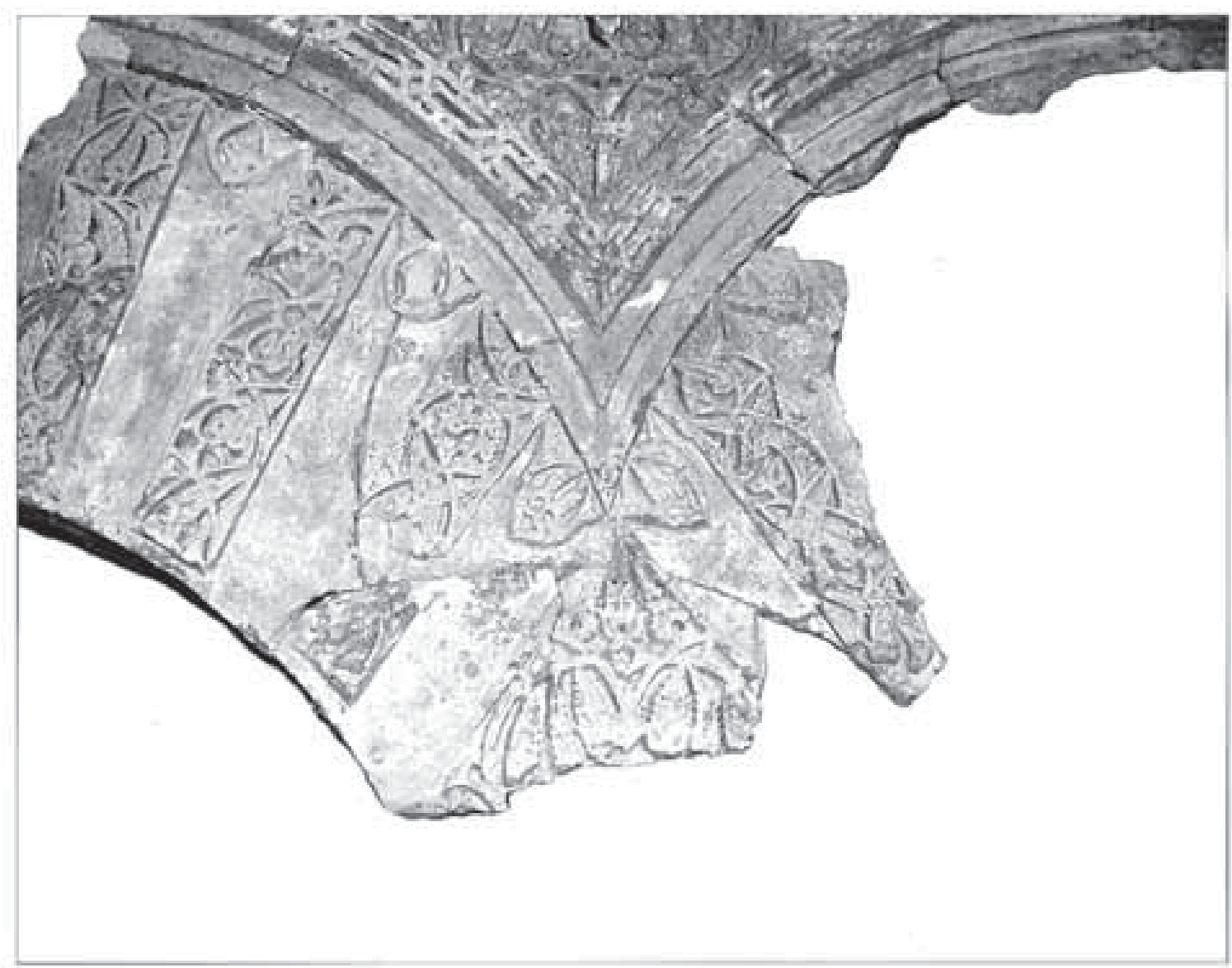

Lámina 10. Dovelas de los aroos 


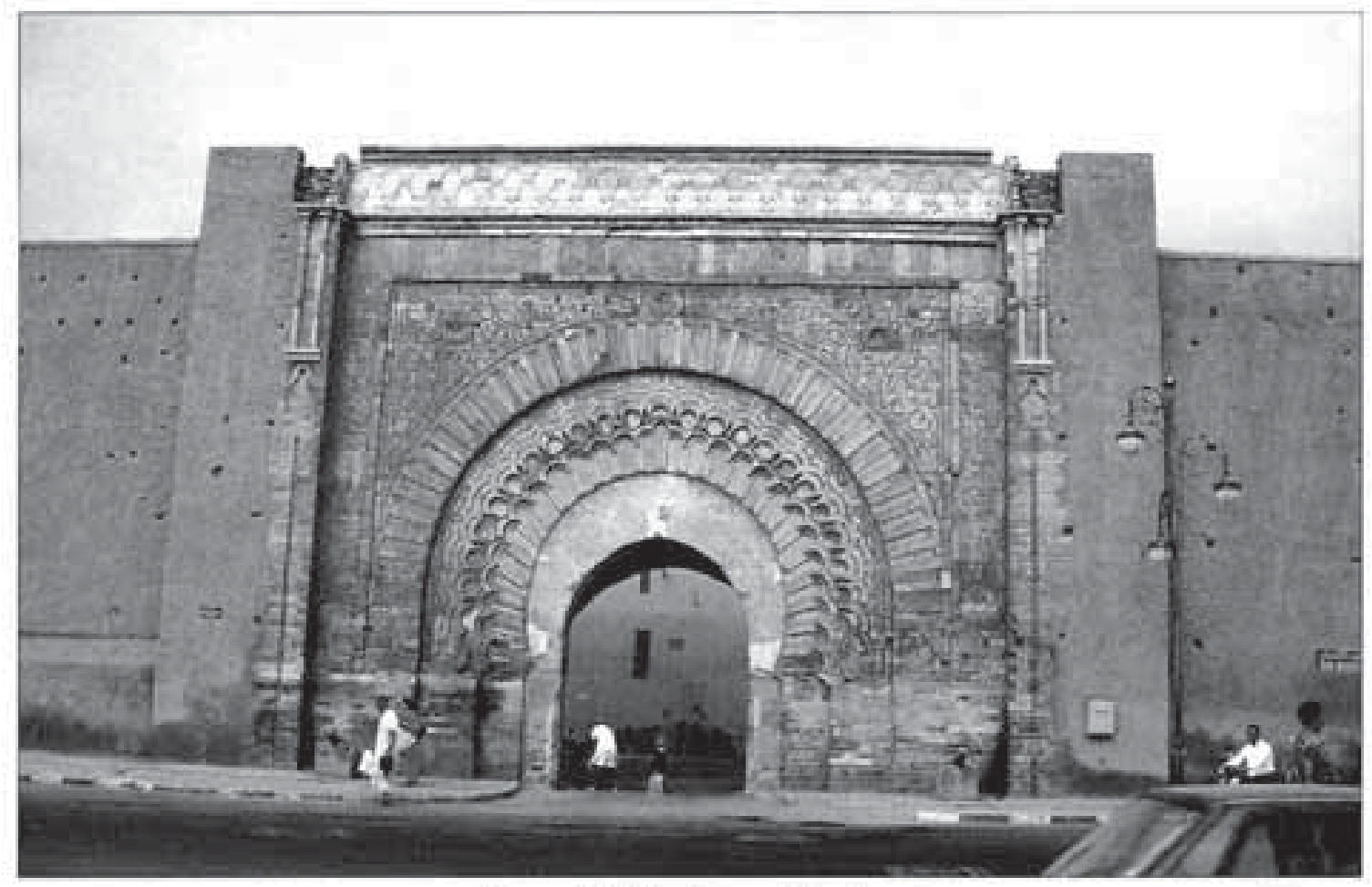

Lámina II. Bảb Agnow (Marrokech) 